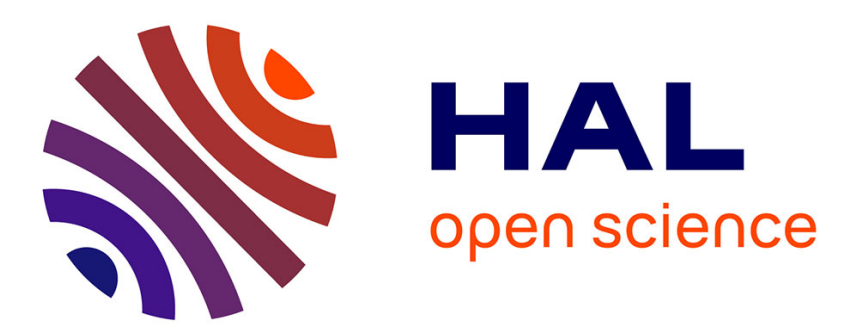

\title{
A Cybernetic Reference Model for Production Systems Using the Viable System Model
}

\author{
Volker Stich, Matthias Blum
}

\section{To cite this version:}

Volker Stich, Matthias Blum. A Cybernetic Reference Model for Production Systems Using the Viable System Model. IFIP International Conference on Advances in Production Management Systems (APMS), Sep 2015, Tokyo, Japan. pp.169-176, 10.1007/978-3-319-22756-6_21 . hal-01417459

\author{
HAL Id: hal-01417459 \\ https://hal.science/hal-01417459
}

Submitted on 15 Dec 2016

HAL is a multi-disciplinary open access archive for the deposit and dissemination of scientific research documents, whether they are published or not. The documents may come from teaching and research institutions in France or abroad, or from public or private research centers.
L'archive ouverte pluridisciplinaire HAL, est destinée au dépôt et à la diffusion de documents scientifiques de niveau recherche, publiés ou non, émanant des établissements d'enseignement et de recherche français ou étrangers, des laboratoires publics ou privés. 


\title{
A Cybernetic Reference Model for Production Systems using the Viable System Model
}

\author{
Volker Stich, Matthias Blum* \\ Institute for Industrial Management (FIR), Campus-Boulevard 55, 52074 Aachen, Germany \\ \{Volker.Stich, Matthias.Blum\}@fir.rwth-aachen.de
}

\begin{abstract}
Designing viable and integrative production systems is challenging for big companies. Researchers often fail to holistically consider the production system. Thus, the aim of this paper is to propose a holistic approach how the supply chain, the production and shop floor planning intermesh. Hereby a Viable System Model was applied. Standardized communication channels were able to be defined among three entities. In conclusion this newly proposed approach enables companies to reduce necessary stocks, production lead times and manpower allocation. This proposed approach boosts the efficiency of all production planning processes. This in turn translates to decreased stocks, shorter lead times and to more efficient manpower allocation. This holistic approach is a key to success for companies, in particular, in high-wage countries.
\end{abstract}

Keywords: Cybernetic reference model, Manufacturing Execution, Production System, Supply Chain, Viable System Model

\section{Background}

Today, manufacturing companies are increasingly confronted with the influences of a dynamic environment and the ensuing continuously increasing planning complexity [1]: Reduced time to markets, increasing product diversity, and increasingly complex multi-tier and world-spanning supply chains are faced with growing interconnectivity of production machinery, manufacturing execution systems, and enterprise resource planning systems under the term Industry 4.0. The Cluster of Excellence "Integrative Production Technology for High Wage Countries" at RWTH Aachen University addresses these opportunities and challenges and aims at resolving the "polylemma of production" which spans along two dilemmas plan-oriented vs. value-oriented production and scale vs. scope [1].

Within the Cluster of Excellence (CoE) on "Integrative Production Technology for High-Wage Countries" several institutes at RWTH Aachen University are conducting research on fundamentals of a sustainable production strategy. As part of the Cluster of Excellence on "Integrative Production Technology for High-Wage Countries" the sub-project D-1 aims at the goal of developing a self-optimizing production network. By applying instruments of self-optimization it leads to a quicker achievement of an

adfa, p. 1, 2011.

(C) Springer-Verlag Berlin Heidelberg 2011 
optimal working point under changing input-parameters. A specific focus is on the consideration of human decisions during the production process when elaborating the cognitive model. To establish socio-technical control loops, it is necessary to understand how human decisions in diffuse working processes are made as well as how cognitive and affective abilities form the human factor within production processes. Thus a cybernetic based reference model of self-optimizing production management, addressing all levels from the supply chain management to the production cell control, has been developed and detailed building on these earlier results. The model has been concretized by individual elements.

\section{Introduction}

On a management level, companies are facing a wide range of challenges in the field of customer demand, dynamic environment conditions and quality problems [2]. Companies have to adapt themselves and their processes to dynamic environment conditions like movements in customer demand, reschedules in supply as well as turbulences in networks [3]. Nevertheless, a successful production management is characterized by high process efficiency and a high availability of information. The challenge is to manage negative consequences, such as wrong decisions in the planning processes, caused by poor communication and conventional solution approaches based on centralized planning methods. Conventional planning and control concepts try to tackle these problems by using highly sophisticated and centralized planning methods. These approaches constrain the ability of companies to react quickly and flexibly on internal and external disturbances [4]. This leads to a slower and more inflexible reaction of companies on internal and external disturbances and thus to an increasing gap between reality and intention [5]. To achieve a higher changeability and a better value-orientation of inter- and inner-company PPC processes, it is necessary to replace the present static arrangement of the central-controlled processes [6].

\section{$3 \quad$ Methodological Approach and Preconditions}

The structure of the cybernetic reference model is derived from principles of the Viable System Model (VSM). The Viable System Model was evolved by STAFFORD BEER in the 1960s as a management model to support managers dealing with complex management processes. It is built on three main principles: viability, recursivity and autonomy. Viability means that a company must react to internal and external disturbances in an appropriate way, in order to sustain its existence. Recursivity is a principle to structure organizational systems in a self-similar way. Hence, a viable system is a composition of nested systems, which are viable systems, too [6, 7]. In this context, autonomy means that a system can act independently as long as it is in accordance with its meta-systems' rules $[8,9]$.

For realizing these principles, BEER introduced a System consisting of a topology with five subsystems (see figure 2). 


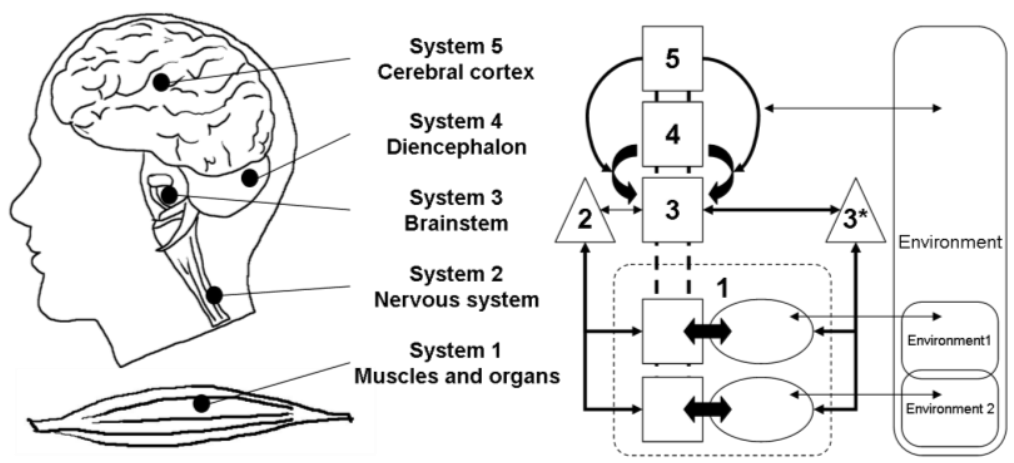

Fig. 1.: Structure of the Viable System Model (Source:Beer 1979, p. 319, Malik 2006, p. 84, Gomez 1978, p. 24, Espejo \& Harnden 1989, p. 99)

System 1 reacts to the development of the relevant operative unit's environment and it coordinates itself with the other operative units with the objective of own stability and whole company's stability. System 2 enables the units of System 1 to solve their own problems allowing decentralized decision-making and solve conflicts between those units. It also carries out the coordination of the operative units regulatory centers. It is an interface between Systems 1 and 3. System 3 has an overall model which is superior to all Systems 1 and their interactions. The operative overall management system ensures optimization of the whole system. By its direct connections with all subsystems it detects simultaneously and in real time everything that occurs in System 1. It is also notified about activities in System 2. System 3 passes on instructions directly to System 1 via the central command axis. The monitoring and validation of information from the operative units are functions of System 3*.

System 3 realizes the control of the orders that are taken in the current operations. It checks the strategic activities provided by System 4 and converts them into tactical operations. Systems 1, 2 and 3 constitute an autonomic system that regulates internal stability and tries to optimize performance within a given structure and criteria. System 4 does an analysis of the external environment and the internal ability to deal with it. It also makes strategic decisions. The internal stability has only sense if the external factors are considered. Reception, elaboration and transmission of information from the environment are tasks of System 4 in order to provide external stability. It is a set of activities, which feeds the highest level of decision making. It must contain a model that represents the idea of the firm in order to inform the top management about which type of firm they are running. System 5 represents the normative level that makes the balance between current operations (System 3) against future's needs (System 4). When there is no balance, System 5 plays the role of judge. System 5 for the firm is the top management and it determines policies and establishes the goals to take decisions $[6,7,9]$. 


\section{Application of the Viable System Model to Cybernetic Production Management}

The Viable System Model (VSM) is, as stated above, serving as a basis for the organizational structure view. It is conceived in analogy to the human nervous system, which has proven its reliability due to the evolutionary process of billions of years to be the most reliably organized and most adaptable system. The VSM specifies the necessary and sufficient constraints for the viability of complex organizations $[6,10]$. These constraints can be subsumed as completeness and recursiveness of the system structure. This leads to the requirements of the basic model.

To cope with the dynamic environment, a cybernetic production management reference model has been developed which integrates the different level of production and production management (see figure 2) $[11,12]$. The main result which has been achieved in previous phases of the project is a cybernetic model structuring a selfoptimizing production management on its different levels, capable to cope with dynamics and to continuously adjust itself. In contrast to the international state of the art the developed model aims to integrate all levels and domains of production and production management. Based on the Viable System Model first developed by Stafford Beer it defines the necessary planning and control tasks as well as the required and sufficient information channels for a self-optimizing production management. It serves as a regulatory framework to allocate the planning and decision models within the overall production management context and to derive design requirements.

Based on these results the project addresses now the comprehensive application of self-optimizing planning and control. This implies the integration of self-optimizing control loops on cell level with those addressing the production planning and control (PPC) as well as supply chain and quality management aspects and will lead to an improvement of planning decisions on different levels of the production network.

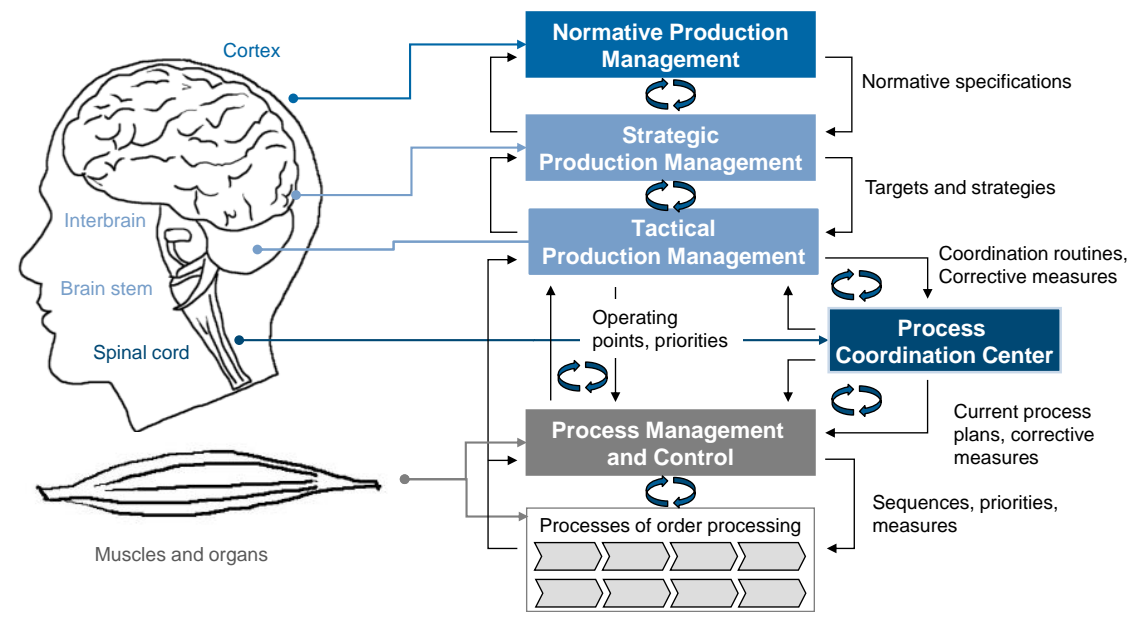

Fig. 2. System structure of the CPM model derived from the VSM 
The Viable System Model provides an adequate structure for consistent integration of trans-disciplinary control loops and their alignment to a super-ordinate target system. It serves as a regulatory framework to allocate the planning and decision models within the overall production management context and to derive design requirements.

To incorporate the different levels of the production systems the levels have been specified. The following figure shows the application of the Viable System Model in production networks and provides an overview of the results of the different levels (see figure 2). As recursion levels the supply chain, the company, the shopfloor, the manufacturing cell and on the bottom the machine level have been defined for the model. The entire model takes on a recursive structure. Recursiveness means that the structure of the model is the same on each level of observation. Any Viable System Model contains and is contained in another viable system model.

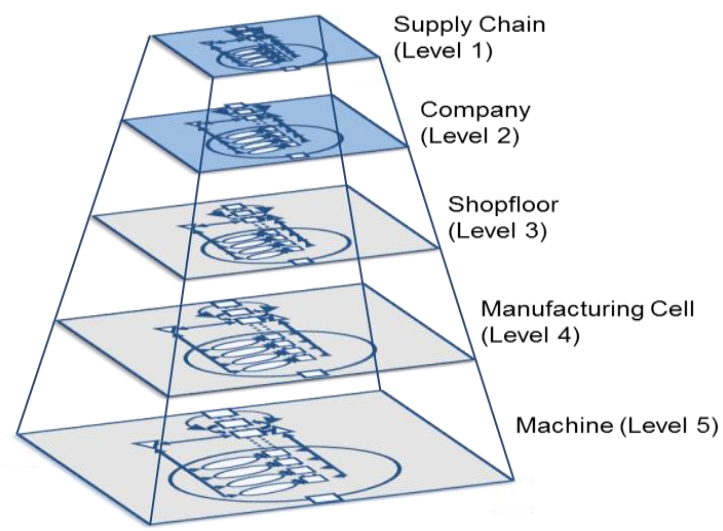

Fig. 3. Recursive organizational level of the Viable System Model

The description of the function of these levels is the central goal of the article at hand and will be shown in the following (see figure 3 ). The figure shows the different levels within the production management and the function of each system in the context of the Viable System Model. To get a more detailed impression of the composition of such a cybernetic based production management model, exemplarily the process and information view for the Supply Chain are described in the following. 


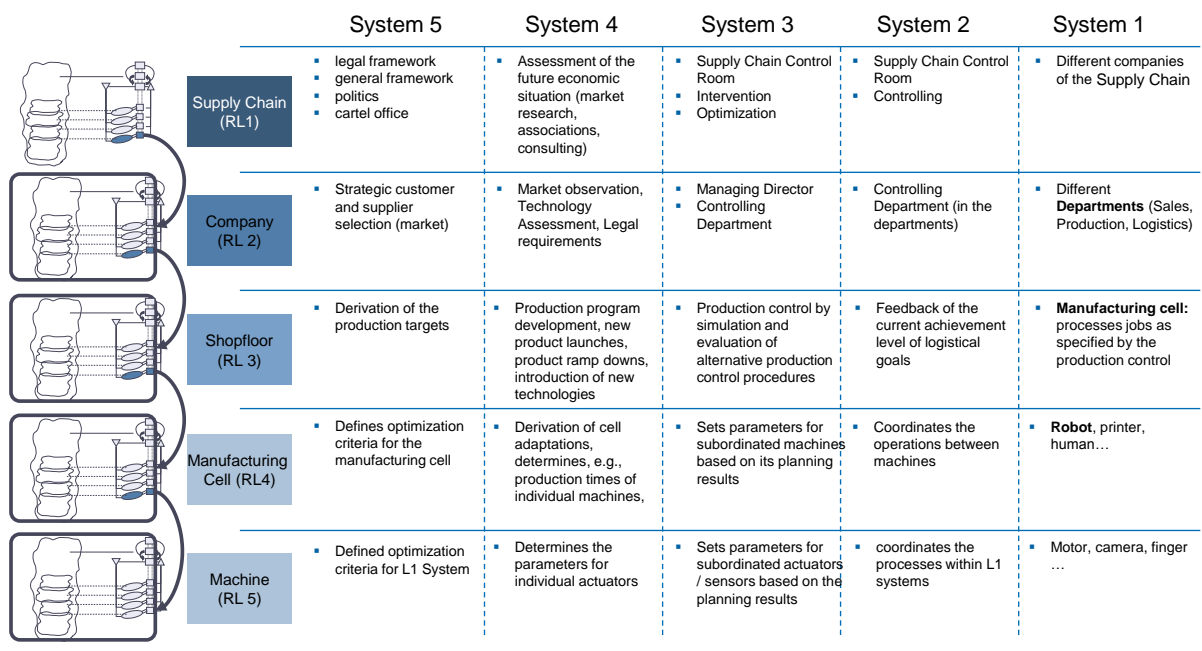

Fig. 4. Information transfer between the different levels

The policy function of a Supply Chain is defined by System 5 and in charge of giving a general respectively a legal framework for the whole Supply Chain. System 5 generates neither know-how nor takes direct action in the Supply Chain. It simply ensures that a balance is maintained between the Supply Chain Control Room (System 3 and 2) and for example the Market Analyses (System 4). When an imbalance develops, i.e. Systems 4 predicts high economic growth and System 3 is not capable to cope with this situation, System 5 will take measures (subsidies, laws etc). By this, System 5 has the power to design the way Supply Chains work without interacting in an operative way. Based on the information System 4 is providing, actions are taken to design the future framework of the Supply Chain.

There are different ways of how the Supply Chain can be affected by its environment or how the Supply Chain can influence it. On the one hand all companies (System 1) can interact with its environment, but only for its own professional expertise. On the other hand System 4 comprises the environments of the separate System 1 and the greater environment. System 4 identifies needs and potential for change, i.e. economic development, new technologies and new markets and transmits the information to System 3. It is also important that the information is exchanged between the separate Systems 4 in the recursion levels. In Supply Chains these tasks are fulfilled by lobbyists to influence the environment, or by Market researchers and associations to collect information. This information is then transferred to System 3 (Supply Chain Control Room) and to other Systems on other recursion levels.

The monitoring and optimization of the various actors in the supply chain is carried out by System 3 and System 2 which represent both together the Supply Chain Control Room. Although, the different companies in the supply chain (System 1) usually are in contact and interact among each other, their behavior is not synchronized. As part of the Supply Chain Control Room System 3 intervenes as necessary and solves conflicts between the companies. To achieve this aim System 3 transfers the infor- 
mation about the operations of the companies into an input-output-matrix and tries to optimize them. The relevant information provides System 2. The aim of System 2 is to coordinate the companies and to avoid oscillations between them. So, System 2 is a system of individual rules and behavior for coordinating operations of the companies. Typical activities of System 2 in the supply chain are for example the rules for joint purchases, the rules for the distribution of parts and the rules for logistical concepts. Furthermore, System 2 is collecting information of the activities such as inventory levels, point of sales data etc., compares the plans to standards and is informing System 3 about deviations to avoid for example the Bullwhip Effect. The gathered information arises from the companies (System 1).

System 1 is directed by the meta-system (System 5-3) and reflects the different companies in the Supply Chain.

In addition, for the other levels of the model (company, shop floor, manufacturing cell and machine) also the functions inside the model have been specified. In order to generate a holistic framework including all levels in the Viable System Model the information transfer will be designed as a relationship model describing the connections between the targets on the different levels of the system.

\section{Summary and further Research}

In today's time companies are facing a wide range of challenges. In this paper, the application of Stafford Beer's Viable System Model (VSM) on the production management has been discussed as one way of handling these challenges. It has been used as a basis to build up a holistic framework for a changeable production management system. After introducing the preconditions of the model, we have derived the structural framework of the cybernetic production management from the Viable System Model and specified the functions of the system elements and their interactions.

Further research is needed to substantiate the presented solution principles for the different tasks in order to verify and validate the model's ability to support the design of control loops. Thereby a specific focus should be dedicated to the determination of the input and output values for each of the systems.

\section{Acknowledgements}

The presented research is result of the Cluster of Excellence (CoE) on "Integrative Production Technology for High-Wage Countries" funded by Deutsche Forschungsgemeinschaft (DFG). Within the CoE "Integrative Production Technology for High-Wage Countries" several institutes at RWTH Aachen University are conducting research on fundamentals of a sustainable production strategy. The authors would like to thank the German Research Foundation DFG for the kind support within the Cluster of Excellence „Integrative Production Technology for High-Wage Countries”. 


\section{References}

1. C. Brecher, Ed., Integrative Production Technology for High-Wage Countries. Springer Heidelberg Dorbrecht London New York, 2012.

2. Brosze, T., Bauhoff, F., Stich, V., Fuchs, S.: High Resolution Supply Chain Management: Resolution of the polylemma of production by information transparency and organizational integration. Advances in Production Management Systems. New Challenges, New Approaches. pp. 325-332 (2010)

3. Schuh, G., Stich, V., Brosze, T., Fuchs, S., Pulz, C., Quick, J., Schürmeyer, M., Bauhoff, F.: High resolution supply chain management. In: German Academic Society for Production Engineering (WGP). Production engineering. Springer, Berlin (2011)

4. Meyer, J., Wienholdt, H.: Wirtschaftliche Produktion in Hochlohnlndern durch High Resolution Supply Chain Management. Supply Chain Management III. 7, pp. $23-27$ (2007)

5. Fleisch, E.: High Resolution Production Management. Wettbewerbsfaktor Produktionstechnik: Aachener Perspektiven. pp. 451-467, Apprimus, Aachen (2008)

6. Beer, S.: Brain of the firm : the managerial cybernetics of organization. The Penguin Press, London (1972)

7. Malik, F.: Strategie des Managements komplexer Systeme. Ein Beitrag zur ManagementKybernetik evolutionärer Systeme. Haupt, Bern (2006)

8. Beer, S.: The heart of enterprise. Wiley, Chichester (1979)

9. Gomez, P.: Die kybernetische Gestaltung des Operations Managements. eine Systemmethodik zur Entwicklung anpassungsfähiger Organisationsstrukturen. Haupt, Bern (1978)

10. Espejo, R.; Harnden, R. (1989): The viable system model. interpretations and applications of Stafford Beer's VSM. Wiley, Chichester.

11. Stich, V. et al. (2009): Viable production system for adaptable and flexible production planning and control processes. In: Proceedings of POMS 20th Annual Conference. POMS, Orlando, Florida, USA.

12. Schuh, G.; Stich, V.; Brosze, T.; Fuchs, S.; Pulz, C.; Quick, J.; Schürmeyer, M.; Bauhoff, F. (2011): High resolution supply chain management. In: German Academic Society for Production Engineering (WGP). Production engineering. Springer, Berlin. 